\title{
International scientific consensus on medical plantar pressure measurement devices: technical requirements and performance
}

\author{
Claudia Giacomozzi $^{(\mathrm{a})}$, Noel Keijsers ${ }^{(\mathrm{b})}$, Todd Pataky(c) and Dieter Rosenbaum $^{(\mathrm{d})}$ \\ (a) Dipartimento di Tecnologie e Salute, Istituto Superiore di Sanità, Rome, Italy \\ ${ }^{(b)}$ Department of Research, Development and Education, Sint Maartenskliniek, \\ Nijmegen, The Netherlands \\ (c) Young Researchers Empowerment Project, Department of Bioengineering, \\ Shinshu University, Ueda, Japan \\ ${ }^{(d)}$ Institute for Experimental Musculoskeletal Medicine, Movement Analysis Lab, \\ University Hospital Münster, Germany
}

\begin{abstract}
Background. Since 2006, the Italian National Institute of Health (ISS) has been conducting independent scientific activities to standardize the technical assessment of plantar pressure measurement devices (PMDs). Material and methods. On the basis of the ISS results, in 2010 the Pedobarographic Group of the International Foot and Ankle Biomechanics community (i-FAB-PG) promoted a Consensus activity about the main technical requirements for the appropriate use of PMDs. The activity relied on a moodlebased on-line forum, documents exchange, discussions, reviews, meetings and a final survey. Results. The participation of clinical and technical researchers, users, and manufacturers, contributed to the delivery of the hereby reported recommendations which specifically regard Medical PMDs in the form of platforms. Conclusions. The i-FAB-PG community reached overall agreement on the recommendations, with a few minor objections which are reported and commented in the document. Relevance. The present document, the highest result achievable within a small scientific community, will hopefully represent the starting point of the wider process of establishing official international guidelines or standards, within scientific communities and standardization organizations.
\end{abstract}

Key words: baropodometry, pressure measurement devices, technical assessment, accuracy, COP estimation.

Riassunto (Consenso scientifico internazionale sui dispositivi medici per la misura delle pressioni plantari: requisiti tecnici e prestazioni). Background. A partire dal 2006, 1'Istituto Superiore di Sanità (ISS) ha condotto attività scientifiche indipendenti mirate alla standardizzazione della valutazione tecnica di dispositivi per la misura della pressione plantare (PMDs). Materiali e metodi. A partire dai risultati dell'ISS, nel 2010 il Gruppo Pedobarografico della International Foot and Ankle Biomechanics community (i-FAB$\mathrm{PG}$ ) ha lanciato un'attività di Consensus relativa ai requisiti tecnici essenziali per un uso appropriato dei PMD. L'attività si è basata su; un forum su piattaforma moodle; scambio, discussione e revisione di documenti; incontri finalizzati; verifica finale di agreement. Risultati. La partecipazione di ricercatori, utilizzatori clinici e tecnici, e produttori, ha contribuito alla definizione delle raccomandazioni qui di seguito riportate, che si riferiscono nello specifico a PMD utilizzati in ambito clinico, in forma di piattaforme. Conclusioni. La comunità i-FAB-PG ha raggiunto un accordo generale sul documento, con solo qualche residua minore obiezione, riportata e commentata nel documento. Rilevanza. È auspicabile che il documento, che costituisce il massimo risultato raggiungibile all'interno di una piccola comunità scientifica, possa rappresentare il punto di partenza di un più ampio processo per la definizione di linee guida ufficiali e di standard, nell'ambito di società scientifiche e di enti normatori.

Parole chiave: baropodometria, dispositivi di misura di pressione, valutazione tecnica, accuratezza, stima centro di pressione (COP). 


\section{INTRODUCTION}

Plantar pressure measurement devices (PMDs) are widespread:

- in the biomechanical research, where they are mainly used to acquire kinetic parameters of foot-floor interaction during gait, running and standing, even though few experimental studies are currently conducted to use PMD outputs as input for finite element models (FEMs) or in general for biomechanical models;

- in the clinical context, as a support to diagnosis, early detection of pathologies, and monitoring during the treatment of not only orthopaedic diseases, but also degenerative, metabolic and systemic diseases, i.e., diabetes and rheumatoid arthritis;

- as a key instrument for the prescription, design and construction of plantar orthoses, in some cases directly linked to CAD/CAM systems (CAD: computer-aided design: CAM: computer-aided manufacturing), and for the assessment of their efficacy.

Whenever a PMD is used for analysing a patient, it should be referred to as "Medical PMD".

Besides the increasing use of PMDs and the increasing number of peer-reviewed, scientific publications discussing PMDs, the lack of standardisation is clearly evident in terms of both instrumentation and methodologies, which renders any comparison and data sharing very difficult and of uncertain validity. The major difficulties to cope with when discussing about PMD technical performance are related to significant differences in sensor technology, matrix spatial resolution, pressure range, sampling rate, calibration procedures, raw data pre-processing. In addition, critical practical issues interfere with the appropriate use of PMDs, i.e. problems associated with patient behaviour, experimental protocol and data post-processing [1].

At least three fundamental steps have to be followed towards standardisation in the use of PMDs:

1. definition and standardisation of tools and protocols for the technical assessment of PMD hardware performance;

2. definition and standardisation of pressure acquisition protocols;

3. definition and standardisation of data processing and reporting.

The present document only deals with the first step. More specifically, it constitutes the final output of a dedicated Consensus Activity ("Agreement on PMD hardware performance"), which has been conducted by the Pedobarographic Group (i-FAB-PG) of the International Foot and Ankle Biomechanics Community (moodle.i-fab.org). Before the community reaches full agreement, just a few minor questions remain to be discussed, mostly related to specific aspects raised by some manufacturers. These aspects are fully reported and commented in the document.

All the statements, recommendations, technical and methodological suggestions hereby reported are the result of: i) preliminary activities at the ISS regarding this specific issue $[2,3]$; ii) online activities within the i-FAB-PG moodle-based forum; iii) background/working material found in the literature [2-18]; iv) document revision, and final on-line survey.

The content of this final i-FAB-PG Consensus Document addresses PMDs, in the form of PLATFORMS intended to be used as Medical PMD for barefoot walking analysis and, optionally, for stabilometric analysis. It may also be applied to different sensor arrangements $-e . g$., wearable or flexible equipment - to perform a partial assessment with the sensor horizontally placed on a plane. In any case, further specification and agreement is needed for sensor performance assessment under flexed conditions.

The i-FAB-PG Consensus Document should be seen in terms of pure scientific consensus, obtained through the joint effort of researchers and manufacturers. The manufacturers and users who will agree to follow the recommendations contained in the document will do so on a purely voluntary basis, without any regulatory constraint. In fact, even though the recommendations are in agreement with the requirements of $\mathrm{EU}$ Directives for Medical Devices, - i.e. they aim at preserving the safety of users and the achievement of the intended use - in no case do they constitute an instrument by which to claim compliance, or demonstrate lack of compliance, with the EU Regulations.

Finally, the present i-FAB-PG Consensus Document, which represents the highest result achievable within the above scientific community, aims to be a starting point for the onset of the complex process of defining official international guidelines and standards, which are expected by wider scientific societies and international standardization organizations.

\section{MATERIALS AND METHODS}

\section{Sequence of actions towards consensus}

Since 2006, the Department of Technology and Health of ISS, the Italian National Institute of Health, has been conducting a scientific project and several related activities aimed to design, validate and implement dedicated testing methods and recommendations for PMD technical assessment [2, 4].

In 2010, ISS organized and hosted the workshop "Assessment of pressure measurement devices (PMDs) for their appropriate use in biomechanical research and in the clinical practice" [5]. A first proposal document was presented at the workshop, dealing with methodological issues and some important recommendations to PMD manufacturers and end users, with special focus on the assessment of PMD hardware performance. A full explanation of the rationale behind each recommendation was also given in the document [2].

The feedback from users and manufacturers who participated in the workshop was used to prepare a second Proposal Document which: i) was disseminated by ISS at the ESM2010 Scientific Meeting. (ESM is the acronym for Emed Scientific Meeting, 
being Emed the capacitive PMD provided by the Manufacturer novel gmbh, Munich, Germany. ESM is a scientific event focussed on foot loading and biomechanics, which takes place every two years, inaugurated and organized by the above Manufacturer and hosted by research and clinical centers all over the world. The 2010 ESM was held in Providence, Rhode Island, USA, on August 14-17 2010, hosted by the Brown University, The Center for Restorative and Regenerative Medicine, in cooperation with the University of Rhode Island); ii) was successively finalized through the ISS moodle-based interactive Forum on PMDs (ISS is hosting the moodle-based interactive web page "ISS-PMDs", which is the ISS forum on hardware performance of plantar pressure measurement devices (PMDs). The page can be found at http://vcms.iss.it/moodle19. A free registration needed to navigate the page can be requested by e-mail message with name and affiliation to claudia.giacomozzi@iss.it). In September 2010 the ISSESM2010 consensus proposal was ready and published in the Forum [19].

At this point, while still maintaining its PMD-related activities with a constant update and interaction on its own dedicated Forum, ISS brought the Consensus Activity to a wider level: in September 2010 the Pedobarographic Group named i-FABPG was created and launched at the meeting of the International Foot and Ankle Biomechanics Community $\left(2^{\text {nd }}\right.$ i-FAB meeting, Seattle, US, Sept 2010). Work was done interactively through the online Forum across 2011, and a first draft of the iFAB-PG Consensus Document on PMD technical performance was disseminated immediately before, and presented during, the dedicated i-FAB-PG session at the ISB meeting in Bruxelles, on July 5th 2011.

Following the general agreement on the Document, a final Agreement Survey was kept open until the end of July 2011 to give all participants the opportunity to make a final revision and comment on the Document. On the basis of the last 10 comments received, the i-FAB-PG Consensus Document was finalised as is reported here. Where agreement could not be reached - mainly due to residual comments or concerns by the manufacturers - a detailed explanation is given in the Document.

For the sake of readability, many technical details proposed and discussed in the drafts of the Document have not been included in this final version, but they are still available on the Forum or may be directly obtained by the leader of the associated Consensus Activity, C. Giacomozzi.

\section{Methodology for document revision and finalisation within $i-F A B-P G$}

Starting from September 2010, background working material and draft documents were uploaded and made available for consultation and downloading at any time by i-FAB-PG Forum participants. Several invitations were sent out to all interested re- searchers, clinical users and manufacturers through several internet dissemination channels and mailing lists. e-mailing was encouraged through the moodle page of the Forum on the proposed discussion topics.

Each time a new document was uploaded on the Forum page, or a new on-line activity was launched, an e-mail message was sent out to all Forum Participants. ISS gave its support also through its own PMDs Forum, by uploading a pdf version of the i-FAB-PG working documents and by alerting its Forum Participants about the i-FAB-PG on-going activities.

Some specific on-line activities were activated for limited time periods, which are briefly summarised here below:

- January $28^{\text {th }}-$ February $11^{\text {th }}$ 2011. A daily open online discussion was "tutored" on the Consensus Document Draft0: it was a constructive phase of the consensus process, even though there was not a true daily on-line discussion among participants for most of them preferred an off-line way of contributing.

- March $1^{\text {st }}-$ June $9^{\text {th }}$ 2011. The revised Draft 1 of the Consensus Document was uploaded and open for comments through the page. As no relevant comments were posted, the Final Document was written with only few minor editorial changes.

- June $10^{\text {th }}-$ July $5^{\text {th }}$ 2011. The Final Complete Consensus Document was uploaded and remained available for comments until its discussion during the i-FAB-PG general meeting in Brussels (July 5th, 2011), open to all ISB participants;

- July $6^{\text {th }}-$ July $31^{\text {st }} 2011$. The Final Survey was launched and kept open to ask for a Final Agreement on the Final Consensus Document; quick questions were delivered to ask whether participants had any residual objection regarding each Table in particular or the entire Document as a whole.

For the general revision procedure, the concept was followed of taking into account each general comment providing a good explanation, contributed at any stage of the revision process, and with a general applicability to Medical PMDs. Each revision was shared and agreed by the PG leaders - i.e. the authors of the present Document - before dissemination. More in detail:

- from Draft0 to Draft1. Seventeen users actively navigated the page during the period; 5 researchers and 3 manufacturers sent back their comments; some other researchers and manufacturers sent their informal comments through private email to activity leaders. None of the points suggested in Draft0 was rebutted; few points were raised for clarification, and proper explanations were added at the beginning or in the core of Draft1; other points were added as suggested by participants. Comments were not added to the 
Table 1 | Basic principles of plantar pressure measurement device (PMD) technical assessment

\section{No. Principle}

$1 \quad$ Market regulations. When used for clinical purposes and unless otherwise specified - clearly and purposely - by the manufacturer, PMD is recognised as a medical device with a measuring function. As such, it must follow the corresponding market regulations of the different countries. In case it is used in a research or sports context, it might or might not be considered as a medical device according to the specific intended use as declared by the manufacturer. In any case, a PMD must always be compliant with regulations dealing with the safety of users (e.g., electrical safety). Prototypes and PMDs for specific research goals might be treated differently - from a regulatory point of view - but they must always be safe for the user.

Being measuring devices - unless a clear statement from the manufacturer defines them not suitable for quantitative measurement - all PMDs should be fully and clearly characterised in terms of their technical specifications. Voluntary standard procedures and guidelines need to be conceived and disseminated to suggest how to assess PMD technical performance, both at the time of their placing on the market (in-factory assessment) and periodically during their lifetime (on-the-field assessment).

2

Standardization and comparability. Pressure measurements should be comparable worldwide within the scientific scenario. It is thus mandatory to reach agreement and consensus on procedures and criteria to standardise the assessment of the technical performance of PMDs and the minimum requirements they are to comply with in order to guarantee the appropriate performance throughout their lifetime (testing equipment must be applicable to at least all medical PMDs on the market).

3 Co-operation. The standardisation of PMD technical assessment and hardware performance requires consensus and agreement on common recommendations and guidelines, which should be suitable for voluntary application to all commercial PMDs and to prototypes when used as medical PMDs. There is also the need for concerted action of scientific communities and PMD manufacturers. Attention is needed from: i) Editors of scientific journals for the publication of high-quality reliable studies; ii) Regulatory Authorities such as EU Notified Bodies for the standardisation of PMD placing on the market as Medical Devices.

$4 \quad$ Testing equipment and procedures for in-factory assessment (addressed to manufacturers)

a) PMDs should be tested, accounting for their final commercial hardware and software arrangement. A suitable testing equipment should be set up and validated, which: i) should apply a well-controlled, uniform force or pressure over local areas or over the entire PMD active area; ii) must have higher precision and accuracy than those expected for the PMD.

b) PMD technical performance should be assessed at least for: sensor response variability over the entire PMD active area; sensor response in terms of absolute value of pressure; sensor hysteresis; sensor response in terms of creep; platform response in terms of accuracy and repeatability of the estimation of COP coordinates.

c) PMD technical performance should be proven over the entire active area when possible; in any case, pressure accuracy and variability should be assessed over the entire active area, not necessarily activating all sensors simultaneously. The testing of the remaining measurement features as in point b) should be performed at least in 5 local areas randomly selected over the entire active area in case it is $\leq 0.25 \mathrm{~m}^{2}$; for larger surfaces, the number of local areas should be increased accordingly.

d) PMD performance should be reported in comparison with reference values when existing and validated.

e) Testing should prove that PMDs intended for the study of pathologies like Diabetes or Rheumatoid Arthritis do maintain an adequate performance at high pressure values which may well exceed $1000 \mathrm{kPa}$ [20-22], and have an adequate spatial resolution in order to accurately measure localized peak pressures.

f) Testing procedures should be tuned to properly assess PMDs to be used in specific scenarios like fast running, jumping, sprinting, jogging (which is beyond the purposes of medical PMDs considered in the present Document).

\section{Comments}

No objection from either researchers or manufacturers

No objection from either researchers or manufacturers

No objection from either researchers or manufacturers

No objection from researchers Residual objections from manufacturers: - one manufacturer specified that the simultaneous loading of the entire area should not be required and might be too complex to be implemented: the sentence "not necessarily activating all sensors simultaneously " has been added for further clarification;

- as for the application of the uniform load, one manufacturer suggested "only uniform pressure over the entire active area": the comment has been reported here but, for the sake of generality, the choice between uniform force or pressure has been maintained;

- one manufacturer objected to the requested comparison of PMD performance with the performance of an "ideal" PMD. Thus the reference to the "ideal" PMD had been removed since it does not exist at the moment of the preparation of this Document. Reference is now suggested with respect to "reference values" once they have been properly identified and validated;

- one manufacturer objected to the request for assessing COP accuracy and repeatability, stating that $\mathrm{COP}$ accuracy may be extrapolated from individual sensor accuracy; being COP one of the most relevant outcomes of a PMD, its direct assessment has been preferred and maintained in the present Document;

- one manufacturer objected that the indication of values over $1000 \mathrm{kPa}$ for some pathologies should be better motivated; some references have thus been added 
Table 1 | Continued

\section{No. Principle}

5 Quality of PMD performance over time (addressed to manufacturers)

a) Manufacturers should properly train the user to the effective, safe and correct use and maintenance of the device; in particular, they should deliver - with a high degree of transparency - the necessary information for the user to know about the implemented data processing procedures (i.e. transparent data display and export procedures)

b) Manufacturers should guarantee that an adequate quality of PMD performance is maintained in time; this may be achieved by periodically calling back and re-testing the device in factory, by implementing periodic spot-checks on-site, or by giving the user adequate instructions to perform proper spot-checks on-site to easily detect significant changes in the PMD performance and promptly alert the manufacturer.

6 Quality of PMD performance over time (addressed to end users)

a) Users should ask the manufacturer for the complete in-factory PMD technical assessment report and for a first assessment soon after the PMD installation. This first on-site assessment should be done locally, once the platform has been installed, and with the assessment tools and procedure for periodic check, so as to render it fully comparable with successive checks: it might be slightly different from the in-factory assessment and, extremely important, reference assessment values must be recorded, which will be fully comparable with the results of successive checks.

b) Users should ask the manufacturer for proper documentation and information for appropriate, effective, safe and correct use and maintenance of the device.

c) Users should monitor the quality of PMD performance over time according to suitable procedures discussed with the manufacturer at the time of PMD delivery and installation. Periodic spot-checks should be performed under repeatable and controlled conditions starting from the first PMD installation. Relevant parameters should be monitored during periodic spot checks.

$7 \quad$ Reading, writing, reviewing scientific papers (addressed to researchers, Editors, ...)

a) Researchers should carefully report on the performance and limitations of the PMD they used for their research and, whenever possible, quantify the difference in performance with respect to a reference medical PMD -once the latter has been eventually defined - (no gold standard for medical PMDs is available at the moment).

b) Consistency, validity and reliability of results and findings based on PMD measurements should be carefully verified when reading and/or reviewing scientific papers. A standard checklist may be of help and should be suggested to the Editors of appropriate journals.

\section{In-factory assessment vs calibration (addressed to manufacturers)}

In-factory PMD assessment should not be confounded with in-factory PMD calibration: the former aims at proving the final product hardware performance with respect to the entire active area when possible or, at least, over 5 randomly selected local areas; the latter should guarantee the accurate calibration of each sensor, and it is usually performed through dedicated procedures and equipment that the manufacturer might not want to disseminate (final calibration curves are only expected in the PMD technical report as proposed in Table 6). Testing equipment and procedures reported in the present document cannot be used for calibration purposes.

\section{Comments}

No objection from researchers.

Residual objections from manufacturers: - one manufacturer objected with the following sentence: "a periodical call-back and/or tests on site seems impossible"

No objection from researchers. Residual objections from manufacturers: - one manufacturer objected with the following sentence: "a periodical call-back and/or tests on site seems impossible"

No objection from manufacturers. Residual objections from researchers:

- one researcher objected that consistency, validity and reliability of results are the responsibility of the authors, not of the reviewer or Editor; he suggested that the checklist should be only used in case there is dispute about PMD data in a specific paper (i.e. not regularly used by reviewers or Editors)

A proper PMD calibration, in fact, should be based on a sensor-by-sensor calibration, which should be done under static and dynamic conditions, and for the whole pressure range. A proper set of software applications should then be conceived, validated and applied to correctly deliver the "calibrated" output of each sensor

COP: centre of pressure; FS: full scale.

document when they were too specific or regarded the performance of specific commercial products. In any case, individual answers were sent to each participant if specifically requested;

- from Draft1 to the Final Document. No comments were posted on the i-FAB-PG Forum; another positive answer was received through the ISS PMD Forum from another manufacturer who requested no changes at all. Only minor editorial changes were shared among the PG leaders, and implemented in the Revised version, which was presented at the i-FAB-PG meeting on July $5^{\text {th }} 2011$ and uploaded to the Forum for the Final Survey;
- from Final Document to i-FAB-PG Consensus Document on PMD Technical Assessment - i.e. the present Document - . Ten comments were received in all, with 3 containing suggestions for further specifications rather than changes. As for the remaining comments, they mainly regarded commercial experiences from Manufacturers: a short explanation accounts for them in the Consensus Tables. Whenever high-level specifications led to disagreement/discussions deserving further investigation, a more general level was maintained for this final Consensus Document with respect to the working documents, whose validity had been implicitly agreed upon by all Participants. 
Table $2 \mid$ Plantar pressure measurement device (PMD) in-factory assessment: minimum set of parameters to be assessed

No. Parameter

1 Pressure distribution: sensor response variability within the entire pressure range

2

\section{Pressure accuracy (absolute values) within the entire pressure range}

3 Hysteresis within the entire pressure range

4

\section{Creep} Accuracy of COP estimation

6 Precision (repeatability) of COP estimation

$7 \quad$ Measurement Bandwidth

8 Sensor cross talk

9 \& Accuracy variation due to usage (to be verified on one sample of the production every time relevant changes are introduced as for technology, mechanics, electronics, etc.)

\section{Description}

Difference in pressure response among all the sensors of the PMD active area, within the entire pressure range

Difference between read and applied pressure, for each sensor, at proper steps of pressure within the entire pressure range.

Maximum difference of pressure readings along the uploading and downloading curve of a slow pressure cycle. For medical PMDs, testing pressure cycle duration should be comparable with slow walking cycle duration $(0.1-1 \mathrm{~Hz})$.

Variation of pressure reading after a $60 \mathrm{~s}$ constant loading at a fixed pressure not lower than $300 \mathrm{kPa}$ [17].

\section{Comments}

No objection from either researchers or manufacturers

No objection from either researchers or manufacturers

No objection from researchers. Residual objection from one manufacturer about the proposed methodology and cycle duration

No objection from researchers. Residual objection from one manufacturer: they suggest that creep should be investigated at different steps of the entire pressure range up to $100 \% \mathrm{FS}$. The rationale for the testing conditions suggested in the present Document is the comparability with standard posturographic examination

No objection from either researchers or manufacturers

Differences between estimated and theoretical COP coordinates, along each axis. A proper number of estimates is needed.

Differences among estimated COP coordinates, along each axis. A proper number of estimates is needed.

Frequency content of the signal spectrum with reference to barefoot walking

Undesired activation of sensors when load/ pressure is applied to different sensors of the PMD active area.

Difference between read and applied pressure, at proper steps of pressure along the entire pressure range, after 16500 cycles of pressure - corresponding to 12 months of regular clinical use $-^{*}$.
No objection from either researchers or manufacturers

No objection from either researchers or manufacturers

No objection from researchers. Residual indication from one manufacturer: they suggest "to investigate cross-talk at various pressures"

No objection from either researchers or manufacturers

${ }^{s}$ This test is only required on a representative sample of the product, i.e. it is not to be repeated on each sample; it should be repeated only when relevant changes are introduced as for technology, mechanics, electronics, etc.

*This estimation comes from interviews with clinicians who regularly use the PMD for patient examination: on average, they examine 1500 patients/year, performing a minimum of 1 static and 10 dynamic trials per patient.

COP: centre of pressure; FS: full scale.

\section{RESULTS}

\section{The i-FAB-PG consensus document}

The outcomes of the described consensus activity have been collected in eight tables. Briefly: Table 1 resumes the basic principles over which agreement has been reached, and which represent the basis for the PMD technical assessment approach; Table 2 describes the parameters which should be included in the minimum set of parameters to be assessed in factory; Table 3 reports the technical requirements a proper test system should have to deliver the parameters listed in Table 2; Table 4 deals with a suggestion for implementing in factory testing proto- cols; Table 5 gives some recommendations in terms of minimum requirements for Medical PMDs addressed to barefoot gait analysis; Table 6 contains a proposal for the Manufacturer's technical report to be associated with the commercial PMD; Table 7 deals with on-site, periodical assessment of PMDs; Table 8 contains a sort of checklist for Authors, Reviewers and Editors to properly judge the consistency of data scientific papers rely on. In each Table comments and explanations are reported when a full agreement had not been reached with respect to the specific point. 
Table 3 | Plantar pressure measurement devices (PMD) in-factory assessment: minimum requirements for testing equipment

\begin{tabular}{|lll|}
\hline No. Description & Requirement \\
\hline $\mathbf{1}$ & Working principle & $\begin{array}{l}\text { The testing equipment may be a pneumatic, air-based or oil-based device, as } \\
\text { well as a force test machine. It must apply a well-controlled uniform load or } \\
\text { pressure - the latter is preferable - over local areas and over the entire PMD } \\
\text { active surface whenever possible. Load/pressure must be tested statically } \\
\text { along the entire pressure range of the PMD. Load/pressure must also be } \\
\text { tested dynamically, at a frequency comparable with gait analysis. Testing } \\
\text { device measurements should be comparable with reference testing devices. }\end{array}$ \\
\hline 2 & Pressure accuracy & control error $\leq 1 \%$ FS
\end{tabular}

2 Pressure accuracy $\quad$ control error $\leq 1 \%$ FS

3 Force accuracy control error $\leq 1 \% \mathrm{FS}$

\section{5}

$7 \quad$ Force range

$9 \quad \begin{aligned} & \text { Slow dynamic testing } \\ & \text { requirements }\end{aligned}$

\section{Measurement bandwidth}

\section{Sensor cross talk}

\section{$12^{\S}$ Accuracy after} continuous loading
Set of suitable pins with variable areas; for each PMD under test, pin area must be smaller than single sensor area
Comments

Residual objections from manufacturers have been reported in Point 10

No objection from either researchers or manufacturers

No objection from either researchers or manufacturers

No objection from either researchers or manufacturers

No objection from either researchers or manufacturers

No objection from either researchers or manufacturers

No objection from either researchers or manufacturers

No objection from either researchers or manufacturers

Loading-unloading cycles of local areas along the entire pressure range, at a frequency in the range $0-1 \mathrm{~Hz}$

Adequate Impact Hammer Test under controlled conditions
No objection from either researchers or manufacturers

No objection from researchers. Residual objection from one manufacturer: they asked for more detailed explanations about the choice

No objection from either researchers or manufacturers

No objection from either researchers or manufacturers

${ }^{\S}$ This test is only required on a representative sample of the product, i.e. it is not to be repeated on each sample; it should be repeated in case relevant changes are introduced as for technology, mechanics, electronics, etc.

*This estimation comes from interviews with clinicians who regularly use the PMD for patient examination: on average, they examine 1500 patients/year, performing a minimum of 1 static and 10 dynamic trials per patient.

COP: centre of pressure; FS: full scale.

Table 4 | Plantar pressure measurement device (PMD) in-factory assessment: suggested testing protocol

\begin{tabular}{|c|c|c|}
\hline No. & Parameter & Protocol \\
\hline 1 & $\begin{array}{l}\text { Pressure } \\
\text { distribution: } \\
\text { sensor response } \\
\text { variability and } \\
\text { accuracy }\end{array}$ & $\begin{array}{l}\text { Sequence of an incremental loading from } 0 \mathrm{kPa} \text { to PMD maximum declared pressure } \\
\text { and down to } 0 \mathrm{kPa} \text { with } 10 \mathrm{~s} \text { of static loading followed by a ramp of } 10 \mathrm{~s} \text { to unload the } \\
\text { PMD and a successive ramp of } 10 \mathrm{~s} \text { to reach the successive loading level; suggested } \\
\text { pressure step: } 50 \mathrm{kPa} \text {; suggested sampling rate: } 5 \mathrm{~Hz} \text {; suggested number of trials: } 3 \text {. } \\
\text { Test should be repeated with PMD sampling rate set at } 100 \mathrm{~Hz} \text { or at the PMD maximum } \\
\text { sampling rate in case it is }<100 \mathrm{~Hz}\end{array}$ \\
\hline 2 & Hysteresis & $\begin{array}{l}\text { Suggested application: small local areas. Suggested protocol: sinusoidal loading- } \\
\text { unloading cycles at frequency in the range } 0.1-1 \mathrm{~Hz} \text {; minimum suggested pressure } \\
\text { range } 0-600 \mathrm{kPa} \text {; suggested sampling rate } 20 \mathrm{~Hz} \text {; suggested number of cycles } \geq 20 \text {. } \\
\text { Test should be repeated with PMD sampling rate set at } 100 \mathrm{~Hz} \text { or at the PMD maximum } \\
\text { sampling rate in case it is }<100 \mathrm{~Hz}\end{array}$ \\
\hline
\end{tabular}

\section{Comments}

No objection from researchers Residual objection from two manufacturers*

No objection from researchers. Residual objection from two manufacturers* 


\begin{tabular}{|c|c|c|c|}
\hline No. & Parameter & Protocol & Comments \\
\hline 3 & Creep & $\begin{array}{l}\text { Suggested application: small local areas. Suggested protocol: pressure fixed at } 300 \mathrm{kPa} \\
\text { and maintained for } 60 \mathrm{~s} \text {; PMD sampling rate } 5 \mathrm{~Hz} \text {. One repetition for each selected area. }\end{array}$ & $\begin{array}{l}\text { No objection from } \\
\text { researchers. } \\
\text { Residual objection from } \\
\text { two manufacturers* }\end{array}$ \\
\hline 4 & $\begin{array}{l}\text { Accuracy and } \\
\text { precision of COP } \\
\text { estimation }\end{array}$ & $\begin{array}{l}\text { Suggested application: small local areas. Suggested device: small table with three pins } \\
\text { covered with soft material, } 120^{\circ} \text { apart, so as to apply controlled and uniform load over } \\
\text { three small areas simultaneously. The device should be constructed to assure that the } \\
\text { theoretical COP coincides with the centre of the device. Suggested protocol: at least } 300 \\
\mathrm{KPa} \text { under each pin; theoretical COP should be initially marked, to be compared with the } \\
\text { estimated location of COP. Acquisition sequence: } 10 \mathrm{~s} \text { of static acquisition in position } 0^{\circ} \\
\text { of each area; } 20 \text {-degree rotation of the device around the centre of the area; acquisition } \\
\text { in position } 20^{\circ} \text {; successive similar rotations and acquisitions up to a total angular } \\
\text { displacement of } 120^{\circ} \text {. PMD sampling rate: at least } 5 \mathrm{~Hz} \text {. } \\
\text { The above sequence may also be performed by using slow loading-unloading cycles } \\
\text { rather than under static conditions; in this case sampling rate should be } 100 \mathrm{~Hz} \text { or as } \\
\text { high as possible if maximum is below } 100 \mathrm{~Hz} \text {. }\end{array}$ & $\begin{array}{l}\text { No objection from } \\
\text { researchers. } \\
\text { Residual objection from } \\
\text { two manufacturers* }\end{array}$ \\
\hline 5 & $\begin{array}{l}\text { Measurement } \\
\text { Bandwidth }\end{array}$ & $\begin{array}{l}\text { Suggested application: small local areas. Suggested protocol: Impact Hammer Test with } \\
\text { controlled load so as to reach a pressure of } 1000 \mathrm{kPa} \text { (load depending on the hammer } \\
\text { impact area). Suggested PMD sampling rate } 100 \mathrm{~Hz} \text { or as high as possible in case it is } \\
<100 \mathrm{~Hz} \text {. Suggested number of trials: } 3 \text {. }\end{array}$ & $\begin{array}{l}\text { No objection from } \\
\text { researchers. } \\
\text { Residual objection from } \\
\text { two manufacturers* }\end{array}$ \\
\hline 6 & Sensor cross talk & $\begin{array}{l}\text { Suggested application: small local areas. Suggested protocol (with the proper set of } \\
\text { pins): application of load/pressure slow loading cycle up to the maximum measurable } \\
\text { pressure (as declared by the manufacturer). Suggested PMD sampling rate: } 20 \mathrm{~Hz} \text {. } \\
\text { Suggested number of trials: } 3 \text {. } \\
\text { The test should be also repeated at PMD sampling rate of } 100 \mathrm{~Hz} \text { or the maximum in } \\
\text { case is it }<100 \mathrm{~Hz} \text {. }\end{array}$ & $\begin{array}{l}\text { No objection from } \\
\text { researchers. Residual } \\
\text { objection from two } \\
\text { manufacturers* }\end{array}$ \\
\hline $7^{\S}$ & $\begin{array}{l}\text { Accuracy after } \\
\text { continuous } \\
\text { loading }\end{array}$ & See point no. 1 of this Table (Table 4), to be applied after 16500 loading cycles & $\begin{array}{l}\text { No objection from } \\
\text { researchers. } \\
\text { Residual objection from } \\
\text { two manufacturers* }\end{array}$ \\
\hline \multicolumn{4}{|c|}{$\begin{array}{l}\text { SThis test is only required on a representative sample of the product, i.e. it is not to be repeated on each sample; it should be repeated in case relevant } \\
\text { changes are introduced as for technology, mechanics, electronics, etc. }\end{array}$} \\
\hline
\end{tabular}
Table 5 | Plantar pressure measurement device (PMD) in-factory assessment: minimum requirements recommended for medical
PMDs for barefoot walking analysis

\begin{tabular}{|c|c|c|c|}
\hline No. & Technical feature & Minimum requirement & Comments \\
\hline 1 & $\begin{array}{l}\text { PMD size of active } \\
\text { area }\end{array}$ & $0.4 \mathrm{~m} \times 0.6 \mathrm{~m}$ & $\begin{array}{l}\text { No objection from researchers. } \\
\text { Residual objection from one manufacturer who } \\
\text { suggested } 0.4 \mathrm{~m} \times 0.5 \mathrm{~m} \text { or } 0.5 \mathrm{~m} \times 0.5 \mathrm{~m} \text {, saying } \\
\text { that } 0.6 \mathrm{~m} \text { is too long for one step only }\end{array}$ \\
\hline 2 & Pressure range & $1500 \mathrm{kPa}$ & $\begin{array}{l}\text { No objection from researchers. } \\
\text { Residual objection from one manufacturer who } \\
\text { stated that "1200 kPa is enough" }\end{array}$ \\
\hline 3 & $\begin{array}{l}\text { Axial spatial } \\
\text { resolution }\end{array}$ & $5 \mathrm{~mm}$ & $\begin{array}{l}\text { No objection from researchers. } \\
\text { Residual objection from one manufacturer* }\end{array}$ \\
\hline 4 & Pressure resolution & $10 \mathrm{kPa}$ & $\begin{array}{l}\text { No objection from researchers. } \\
\text { Residual objection from one manufacturer* }\end{array}$ \\
\hline 5 & Sampling rate & $\begin{array}{l}100 \mathrm{~Hz} \text {. Additionally: } \\
\text { 1) possibility to work at lower rates; 2) possibility to go up } \\
\text { to } 200 \mathrm{~Hz} \text { without loosing accuracy and precision). } \\
\text { Higher frequencies might be more suitable for different } \\
\text { uses (running, jumping, and other sports-related activities). }\end{array}$ & $\begin{array}{l}\text { No objection from researchers. } \\
\text { Residual objection from one manufacturer who } \\
\text { objected that " } 200 \mathrm{~Hz} \text { might be necessary" [18] }\end{array}$ \\
\hline
\end{tabular}


Table $5 \mid$ Continued

\begin{tabular}{|c|c|c|c|}
\hline No. & Technical feature & Minimum requirement & Comments \\
\hline 6 & Pressure accuracy & $\begin{array}{l}\text { Error }<5 \% \text { FS for each sensor up to the highest possible } \\
\text { sampling rate }\end{array}$ & $\begin{array}{l}\text { No objection from researchers. } \\
\text { Residual objection from one manufacturer* }\end{array}$ \\
\hline 7 & Force accuracy & $\begin{array}{l}\text { Error }<5 \% \mathrm{FS} \text { over at least } 5 \text { small random areas } \\
\text { of about } 7 \mathrm{~cm}^{2} \text { each }\end{array}$ & $\begin{array}{l}\text { No objection from researchers. } \\
\text { Residual objection from one manufacturer* }\end{array}$ \\
\hline 8 & Pressure variability & $\begin{array}{l}<10 \% \text { over the entire platform and } \\
\text { for the entire pressure range }\end{array}$ & $\begin{array}{l}\text { No objection from researchers. } \\
\text { Residual objection from one manufacturer* }\end{array}$ \\
\hline 9 & Hysteresis & $\begin{array}{l}<5 \% \text { of the used range with a loading-unloading range up } \\
\text { at least half of the entire pressure range }\end{array}$ & $\begin{array}{l}\text { No objection from researchers. } \\
\text { Residual objection from one manufacturer* }\end{array}$ \\
\hline 10 & Creep & $\begin{array}{l}<5 \mathrm{kPa} / \mathrm{s} \text { in case the PMD is only intended for dynamic } \\
\text { analysis; }<0.15 \mathrm{kPa} / \mathrm{s} \text { in case the PMD is also intended } \\
\text { for static posturography }\end{array}$ & $\begin{array}{l}\text { No objection from researchers. } \\
\text { Residual objection from one manufacturer* }\end{array}$ \\
\hline 11 & $\begin{array}{l}\text { Spatial accuracy } \\
\text { and precision in } \\
\text { COP estimation }\end{array}$ & $<2 \mathrm{~mm}$ along each axis & $\begin{array}{l}\text { No objection from either researchers or } \\
\text { manufacturers }\end{array}$ \\
\hline $12^{\S}$ & $\begin{array}{l}\text { Pressure accuracy } \\
\text { after } 16500 \text { cycles }\end{array}$ & $\begin{array}{l}\text { Error }<5 \% \text { FS for each sensor up to the highest possible } \\
\text { sampling rate (data from the representative tested sample) }\end{array}$ & $\begin{array}{l}\text { No objection from either researchers or } \\
\text { manufacturers }\end{array}$ \\
\hline 13 & $\begin{array}{l}\text { Measurement } \\
\text { bandwidth }\end{array}$ & $\geq 20 \mathrm{~Hz}$ & $\begin{array}{l}\text { No objection from researchers. } \\
\text { Residual objection from one manufacturer* }\end{array}$ \\
\hline 14 & Cross-talk & $\begin{array}{l}<5 \% \text { (as for both number of sensors and load due } \\
\text { to cross-talk) in both directions }\end{array}$ & $\begin{array}{l}\text { No objection from either researchers or } \\
\text { manufacturers }\end{array}$ \\
\hline
\end{tabular}

Table 6 | Pressure measurement device (PMD) in-factory assessment: proposal for manufacturer technical report

\begin{tabular}{|c|c|c|c|c|}
\hline No. & & Parameter & Indication/units & Comments \\
\hline 1 & $\begin{array}{l}\text { PMD Technical } \\
\text { data }\end{array}$ & Size & $\mathrm{cm}$ or $\mathrm{mm}$ for each direction & $\begin{array}{l}\text { No objection from either } \\
\text { researchers or manufacturers }\end{array}$ \\
\hline 2 & & Active area & $\mathrm{cm}$ or $\mathrm{mm}$ for each direction & $\begin{array}{l}\text { No objection from either } \\
\text { researchers or manufacturers }\end{array}$ \\
\hline 3 & & Mass & $\mathrm{kg}$ & $\begin{array}{l}\text { No objection from either } \\
\text { researchers or manufacturers }\end{array}$ \\
\hline 4 & & Thickness & $\mathrm{mm}$ & $\begin{array}{l}\text { No objection from either } \\
\text { researchers or manufacturers }\end{array}$ \\
\hline 5 & & Sensor Technology & $\begin{array}{l}\text { Short description of sensor technology and basics } \\
\text { of sensor working principles }\end{array}$ & $\begin{array}{l}\text { No objection from either } \\
\text { researchers or manufacturers }\end{array}$ \\
\hline 6 & & Pressure range & $\mathrm{kPa}$ & $\begin{array}{l}\text { No objection from either } \\
\text { researchers or manufacturers }\end{array}$ \\
\hline 7 & & Pressure resolution & $\mathrm{kPa}$ & $\begin{array}{l}\text { No objection from either } \\
\text { researchers or manufacturers }\end{array}$ \\
\hline 8 & & Spatial resolution & $\mathrm{mm}$ for each direction & $\begin{array}{l}\text { No objection from either } \\
\text { researchers or manufacturers }\end{array}$ \\
\hline 9 & & Sampling rate & $\mathrm{Hz}$ & $\begin{array}{l}\text { No objection from either } \\
\text { researchers or manufacturers }\end{array}$ \\
\hline 10 & & $\begin{array}{l}\text { Compliance with } \\
\text { International Regulations }\end{array}$ & $\begin{array}{l}\text { Reference to eventual PMD Certification or } \\
\text { compliance with International Regulations and } \\
\text { Standards }\end{array}$ & $\begin{array}{l}\text { No objection from either } \\
\text { researchers or manufacturers }\end{array}$ \\
\hline
\end{tabular}




\begin{tabular}{|c|c|c|c|c|}
\hline No. & & Parameter & Indication/units & Comments \\
\hline 11 & $\begin{array}{l}\text { PMD performance: } \\
\text { calibration }\end{array}$ & Calibration procedures & $\begin{array}{l}\text { Short description of calibration procedures and } \\
\text { equipment, including reference to standards, if any }\end{array}$ & $\begin{array}{l}\text { No objection from either } \\
\text { researchers or manufacturers }\end{array}$ \\
\hline 12 & & Main calibration outcomes & $\begin{array}{l}\text { Calibration curves and/or relevant outcomes } \\
\text { (mean and sd values) }\end{array}$ & $\begin{array}{l}\text { No objection from either } \\
\text { researchers or manufacturers }\end{array}$ \\
\hline 13 & & $\begin{array}{l}\text { Need/indications for on-site } \\
\text { calibration or equilibration } \\
\text { procedures }\end{array}$ & $\begin{array}{l}\text { Detailed description of what the user is expected to } \\
\text { do to use a well-calibrated device }\end{array}$ & $\begin{array}{l}\text { No objection from either } \\
\text { researchers or manufacturers }\end{array}$ \\
\hline 14 & $\begin{array}{l}\text { PMD in-factory } \\
\text { assessment }\end{array}$ & $\begin{array}{l}\text { Assessment procedures } \\
\text { and equipment }\end{array}$ & $\begin{array}{l}\text { Short description of assessment procedures and } \\
\text { equipment, including reference to standards if any }\end{array}$ & $\begin{array}{l}\text { No objection from either } \\
\text { researchers or manufacturers }\end{array}$ \\
\hline 15 & & Pressure accuracy & $\begin{array}{l}\text { Clear indication of pressure accuracy along the } \\
\text { entire pressure range }\end{array}$ & $\begin{array}{l}\text { No objection from either } \\
\text { researchers or manufacturers }\end{array}$ \\
\hline 16 & & Pressure variability & $\begin{array}{l}\text { Clear indication of pressure variability along the } \\
\text { entire pressure range }\end{array}$ & $\begin{array}{l}\text { No objection from either } \\
\text { researchers or manufacturers }\end{array}$ \\
\hline 17 & & Hysteresis & $\%$ of applied pressure range & $\begin{array}{l}\text { No objection from either } \\
\text { researchers or manufacturers }\end{array}$ \\
\hline 18 & & $\begin{array}{l}\text { Pressure accuracy after } \\
16500 \text { cycles }\end{array}$ & $\begin{array}{l}\text { Clear indication of pressure accuracy along the } \\
\text { entire pressure range }\end{array}$ & $\begin{array}{l}\text { No objection from either } \\
\text { researchers or manufacturers }\end{array}$ \\
\hline 19 & & Creep & $\mathrm{kPa} / \mathrm{s}$ & $\begin{array}{l}\text { No objection from either } \\
\text { researchers or manufacturers }\end{array}$ \\
\hline 20 & & $\begin{array}{l}\text { Spatial accuracy in COP } \\
\text { estimation }\end{array}$ & $\mathrm{mm}$ for each direction & $\begin{array}{l}\text { No objection from either } \\
\text { researchers or manufacturers }\end{array}$ \\
\hline 21 & & $\begin{array}{l}\text { Spatial precision } \\
\text { (repeatability) in COP } \\
\text { estimation }\end{array}$ & $\mathrm{mm}$ for each direction & $\begin{array}{l}\text { No objection from either } \\
\text { researchers or manufacturers }\end{array}$ \\
\hline 22 & & Bandwidth & $\begin{array}{l}\text { Indication of } 3 \mathrm{~dB} \text { bandwidth (Hz). Short description } \\
\text { of the assessment method (especially if different } \\
\text { from Instrumented Impact Hammer Test) }\end{array}$ & $\begin{array}{l}\text { No objection from either } \\
\text { researchers or manufacturers }\end{array}$ \\
\hline 23 & & Cross-talk & $\begin{array}{l}\% \text { of error with respect to number of sensors; } \\
\% \text { of error with respect to load }\end{array}$ & $\begin{array}{l}\text { No objection from either } \\
\text { researchers or manufacturers }\end{array}$ \\
\hline 24 & $\begin{array}{l}\text { PMD use and } \\
\text { maintenance }\end{array}$ & Indications for proper use & $\begin{array}{l}\text { Clear description of PMD intended use, limitations, } \\
\text { drawbacks, proper installation for a correct } \\
\text { use (proper surface, installation at a level, ..), } \\
\text { suggestions for problem solving, ... }\end{array}$ & $\begin{array}{l}\text { No objection from either } \\
\text { researchers or manufacturers }\end{array}$ \\
\hline 25 & & $\begin{array}{l}\text { Indications for on-site spot- } \\
\text { checks }\end{array}$ & $\begin{array}{l}\text { Detailed description of on-site testing procedures } \\
\text { and equipment if any, PMD maintenance } \\
\text { management, ... }\end{array}$ & $\begin{array}{l}\text { No objection from researchers. } \\
\text { Residual objections from one } \\
\text { manufacturer who stated } \\
\text { that "on site calibration is not } \\
\text { conceivable" }\end{array}$ \\
\hline
\end{tabular}

\section{DISCUSSION AND CONCLUSIONS}

The i-FAB-PG Consensus Document hereby reported is the first attempt of a Scientific Community at having users and manufacturers work together for the definition of recommendations to standardise the assessment of PMD hardware performance. Notwithstanding the effort and the time devoted to discussing and finding agreement on several issues, and the valuable results obtained up to now, the Document should still be reckoned as a merely scientific initiative of only a part of the entire world scientific community involved in PMD research and applications.
At a more general level, at least another three project lines should stem from this first experience, namely: - the preparation of official guidelines as a result of a worldwide Consensus activity. ISS is deeply involved in the formulation of official guidelines at national level in the field of Public Health, and is thus ready to start and lead such an initiative at the International level. The process should be based on an active collaboration with the dedicated scientific societies all over the world; the activities ISS is conducting within the Italian Society of Movement Analysis in Clinics (SIAMOC) already represents a first step in this direction. Equally important 
in this sense are all the dissemination activities aimed at sharing a deeper knowledge of PMDs technology, potentialities and criticalities with users at different levels and in different scenarios;

- the definition of a clearer regulatory scenario: an issue of particular relevance in clinical environ- ments, where PMDs are to be intended as Medical Devices. ISS has already started a regulatory activity in this direction within the Italian Institutes for Standards, for the submission of a PMD-specific Standard; hopefully, this activity will be eventually taken to the European level;

Table 7 | Plantar pressure measurement devices (PMD) periodic on-site assessment: criteria and minimum requirements

\begin{tabular}{|c|c|c|}
\hline No. & Parameters & testing suggestions \\
\hline $\begin{array}{l}0 \\
\text { (common) }\end{array}$ & $\begin{array}{l}\text { Changes in the periodic test } \\
\text { output }>10 \% \text { with respect to } \\
\text { the first Test, for at least one of } \\
\text { the recommended parameters, } \\
\text { should be reported and } \\
\text { discussed with the manufacturer } \\
\text { (thresholds may be lower than } \\
10 \% \text { based on agreement with } \\
\text { the manufacturer or special } \\
\text { needs of the user) }\end{array}$ & $\begin{array}{l}\text { Periodic tests should be } \\
\text { repeated at a frequency } \\
\text { suggested/agreed with the } \\
\text { manufacturer. } \\
\text { Suggested maximum interval } \\
\text { between two successive tests: } \\
1 \text { year or } 16500 \text { footsteps. } \\
\text { A Periodic Test is suggested } \\
\text { before conducting a specific } \\
\text { research acquisition campaign. }\end{array}$ \\
\hline 1 & $\begin{array}{l}\text { Pressure distribution: } \\
\text { sensor response variability }\end{array}$ & $\begin{array}{l}\text { Periodic tests on randomly } \\
\text { selected areas to cover the } \\
\text { entire active surface. An } \\
\text { accurate, small portable device } \\
\text { may be used in conjunction } \\
\text { with some loads so as to apply } \\
\text { a certain pressure over small } \\
\text { regions. } \\
\text { Tests should be highly } \\
\text { repeatable }\end{array}$ \\
\hline
\end{tabular}

2

Pressure accuracy

(absolute values)

3

Hysteresis

4

Creep

Accuracy of COP estimation

6

Precision (repeatability)

of COP estimation

Bandwidth

8
Cross-talk

\section{Requirements}

It is mandatory that:

- the tests be first performed soon after

the PMD installation;

- the same areas be always tested during

the successive spot-checks;

- the same testing device, procedures and

conditions be used in each successive

spot-check.

Pressures in the range 200-300 $\mathrm{kPa}$ may be sufficient for a spot-check (which allows for relative light and portable devices); pressures should be well controlled in the successive periodic tests; RMSE of pressure values averaged over each area should be compared with reference test outputs (taken at the time of PMD installation): in case of changes greater than $10 \%$, the manufacturer should be asked for a more accurate assessment.

See no.1

Qualitative suggested test: "thumb press"

See no.1

Tests may be performed with a portable device working on a similar principle as in Table 4, no.4.

See no. 5

Impact Hammer Test; data acquisition at the maximum available sampling rate

See Table 4 no. 6 , to be done with a portable set of pins
See no.1, but higher pressures are desirable in this case, and \% changes should be calculated for averaged peak pressures.

"Thumb press" on the plate may give a qualitative indication of short-term hysteresis and linearity up to low pressure values

See no. 1: tests should last at least 60 seconds, and \% changes should be calculated for pressure gradient in $\mathrm{kPa} / \mathrm{s}$.

Testing protocols and indicators should be similar to those reported in Table 4, no. 4. Pressures should never be lower than 200 $\mathrm{kPa}$ \% changes should be calculated for RMSE of COP accuracy (i.e. with respect to the theoretical $\mathrm{COP}$ ) along each axis.

See \#5, but with attention to $\%$ changes of RMSE of COP repeatability along each axis.

If the test device is not instrumented and the Impact Hammer Test Conditions not well controllable, at least the maximum recordable pressure should be reached during the load pulse.

It should be verified that the maximum recordable pressure is reached during pin loading.

\section{Comments}

No objection from either researchers or manufacturers*

No objection from either researchers or manufacturers*

No objection from either researchers or manufacturers*

No objection from either researchers or manufacturers*

No objection from either researchers or manufacturers*

No objection from either researchers or manufacturers ${ }^{*}$

No objection from either researchers or manufacturers*

No objection from either researchers or manufacturers*

No objection from either researchers or manufacturers* 


\begin{tabular}{|c|c|c|c|}
\hline No. & Suggested action & Suggested information & Comments \\
\hline 1 & Check for: & Technical data (see Table 6, no. 1 to 10) & No objection from either researchers or manufacturers* \\
\hline 2 & & In-factory assessment data (see Table 6, no. 14 to 23) & No objection from either researchers or manufacturers* \\
\hline 3 & & $\begin{array}{l}\text { Results of on-site assessment before } \\
\text { performing the study }\end{array}$ & No objection from either researchers or manufacturers* \\
\hline 4 & & Basic PMD outcomes in terms of absolute values & No objection from either researchers or manufacturers* \\
\hline 5 & Check for: & $\begin{array}{l}\text { Comparison with a reference PMD performance } \\
\text { (when eventually available) }\end{array}$ & No objection from either researchers or manufacturers* \\
\hline 6 & & $\begin{array}{l}\text { Discussion on limitations and comparability } \\
\text { of the PMD outcomes }\end{array}$ & No objection from either researchers or manufacturers* \\
\hline 7 & & $\begin{array}{l}\text { Validity and consistency of basic PMD outcomes } \\
\text { (essential requirements for validity of further analysis) }\end{array}$ & No objection from either researchers or manufacturers* \\
\hline
\end{tabular}

- continuous research and technology development to design and validate innovative and valuable methods and instruments for PMD testing, both on the bench and in the field;

After this Consensus Document, i-FAB-PG will hopefully continue the discussion and investigation of the other issues relevant to the appropriate use of PMDs: those strictly related to measurement protocols, and data extraction and interpretation.

\section{Acknowledgements}

The authors thank all i-FAB-PG and i-FAB participants who gave their best and rendered consensus activity a success; special thanks are due to the following researchers and manufacturers who actively contributed to the preparation and revision of the documents (some of them, external to the i-FAB-PG, gave

\section{References}

1. Giacomozzi C. Potentialities and criticalities of plantar pressure measurements in the study of foot Biomechanics: devices, methodologies and applications. Chapter 11: In: Biomechanics in applications. Vaclav K (Ed.). InTech Publication, September 2011. ISBN 978-953-307-969-1. (Open access book available from: www.intechweb.org/books/show/title/biomechanics-in-applications, last check July 2012). http://dx.doi.org/10.5772/23464

2. Giacomozzi C. Hardware performance assessment recommendations and tools for baropodometric sensor systems. Ann Ist Super Sanità 2010;46(2):158-67. http://dx.doi.org/10.4415/ANN_10_02_09

3. Giacomozzi C. Performance of plantar pressure measurement devices (PMDs): update on consensus activities. Ann Ist Super Sanità 2010;46(4):343-5. http://dx.doi.org/10.4415/ANN_10_04_01

4. Giacomozzi C. Appropriateness of plantar pressure measurement devices: a comparative technical assessment. Gait Posture. 2010;32(1):141-4. DOI: 10.1016/j.gaitpost.2010.03.014 http://dx.doi.org/10.1016/j.gaitpost.2010.03.014 their contribution through the ISS-PMDs Forum): i) researchers: Bus SA; D'Amico M; Davenport C; Evans A; Gapeyeva H; Lau HC; Mickle K; Murphy N; Roberts A; Russell J; Sawacha Z; Segers V; ii) manufacturers: AMCUBE; MEDILOGIC; NOVEL; RSSCAN, TEKSCAN. The authors are also grateful to Monica Brocco for the English editing of the manuscript.

\section{Conflict of interest statement}

There are no potential conflicts of interest or any financial or personal relationships with other people or organizations that could inappropriately bias conduct and findings of this study. Manufacturers' indications and suggestions have been taken into account only when based on a strong scientific rationale, and having general applicability.

Received on 5 May 2012.

Accepted on 11 June 2012.

5. Giacomozzi C (Ed.). Assessment of pressure measurement devices (PMDs) for their appropriate use in biomechanical research and in the clinical practice. Istituto Superiore di Sanità. Rome, Italy, May 10, 2010. Abstract book. Roma: ISS; 2010. 27 p. (www.iss.it/publ/cong/cont.php?id=2393\&la ng $=1 \&$ tipo $=6 \&$ anno $=2010$, last check February 2012).

6. Giakas G, Baltzopoulos V. Time and frequency domain analysis of ground reaction forces during walking: an investigation of variability and symmetry. Gait \& Posture 1997;5(3):189-97. DOI: 10.1016/S0966-6362(96)01083-1 http://dx.doi.org/10.1016/S0966-6362(96)01083-1

7. Antonsson EK, Mann RW. The frequency content of gait. Journal of Biomechanics 1985;18(1):39-47. DOI: 10.1016/00219290(85)90043-0 http://dx.doi.org/10.1016/0021-9290(85)90043-0

8. Della Croce U, Cappozzo A. A spot-check for estimating stereophotogrammetric errors. Med Biol Eng Comput 2000; 38:260-6. http://dx.doi.org/10.1007/BF02347045 
9. Cappozzo A, Della Croce U, Catani F, Leardini A, Fioretti $\mathrm{S}$, Maurizi M, et al. Stereometric system accuracy tests. In: Measurement and data processing methodology in clinical movement analysis-preliminary. CAMARC II Internal Report; 1993.

10. Ehara Y, Fujimoto H, Miyazaky S, Tanaka S, Yamamoto S. Comparison of the performance of 3-D camera systems. Gait \& Posture 1995;3:166-9. DOI 10.1016/0966-6362(95)99067-U http://dx.doi.org/10.1016/0966-6362(95)99067-U

11. Ehara Y, Fujimoto H, Miyazaky S, Mochimaru M, Tanaka S, Yamamoto S. Comparison of the performance of 3D camera systems II. Gait \& Posture 1997;5:251-5. DOI 10.1016/S0966-6362(96)01093-4

http://dx.doi.org/10.1016/S0966-6362(96)01093-4

12. Cappozzo A, Catani F, Leardini A, Benedetti MG, Della Croce U. Position and orientation of bones during movement: experimental artefacts. Clin Biomech 1996;11(2):90100. DOI 10.1016/0268-0033(95)00046-1

http://dx.doi.org/10.1016/0268-0033(95)00046-1

13. Holden JP, Selbie S, Stanhope SJ. A proposed test to support the clinical movement analysis laboratory accreditation process. Gait \& Posture 2003;17:205-13. DOI 10.1016/S09666362(02)00088-7

http://dx.doi.org/10.1016/S0966-6362(02)00088-7

14. Lewis A, Stewart C, Postans N, Trevelyan J. Development of an instrumented pole test for use as a gait laboratory quality check. Gait \& Posture 2007;26(2):317-22. Epub 2006 Oct 25. DOI 10.1016/j.gaitpost.2006.09.003

http://dx.doi.org/10.1016/j.gaitpost.2006.09.003

15. Collins SH, Adamczyk PG, Ferris DP, Kuo AD. A simple method for calibrating force plates and force treadmills using an instrumented pole. Gait \& Posture 2009;29(1):5964. DOI 10.1016/j.gaitpost.2008.06.010 http://dx.doi.org/10.1016/j.gaitpost.2008.06.010
16. Lord M. Spatial resolution in plantar pressure measurement. Medical Engineering and Physics 1997;19(2):140-4. DOI 10.1016/S1350-4533(96)00057-4 http://dx.doi.org/10.1016/S1350-4533(96)00057-4

17. Kapteyn TS, Bles W, Njiokiktjien, Kodde L, Massen CH, Mol JMF. Standardization in platform stabilometry being a Part of Posturography. Agressologie 1983;24(7):321-6.

18. Simon SR, Paul IL, Mansour J, Munro M, Abernethy PJ, Radin EL. Peak dynamic force in human gait. $J$ Biomech 1981;14(12):817-22. DOI 10.1016/0021-9290(81)90009-9 http://dx.doi.org/10.1016/0021-9290(81)90009-9

19. Giacomozzi C. A further step towards Consensus on hardware performance and technical assessment of pressure measurement devices: the ESM2010 proposal; uploaded on the ISS-PMDs Moodle Forum on November 2010 (web document available for registered participants from: http://vcms.iss.it/moodle19/file.php/57/ESM2010_ consensus_on_PMD_TA_FINAL.pdf, last check July 2012).

20. Solano MP, Prieto LM, Varon JC, Moreno M, Boulton AJ. Ethnic differences in plantar pressures in diabetic patients with peripheral neuropathy. Diabetic Medicine 2008; 25(4):505-7. DOI 10.1111/j.1464-5491.2008.02381.x http://dx.doi.org/10.1111/j.1464-5491.2008.02381.x

21. Giacomozzi C, Martelli F. Peak pressure curve: an effective parameter for early detection of foot functional impairments in diabetic patients. Gait \& Posture 2006;23(4):464-70. DOI 10.1016/j.gaitpost.2005.06.006. http://dx.doi.org/10.1016/j.gaitpost.2005.06.006

22. Giacomozzi C, Martelli F, Nagel A, Schmiegel A, Rosenbaum D. Cluster analysis to classify gait alterations in rheumatoid arthritis using peak pressure curves. Gait \& Posture 2009; 29(2):220-4. DOI 10.1016/j.gaitpost.2008.08.004. http://dx.doi.org/10.1016/j.gaitpost.2008.08.004 